\title{
A Research Evaluating Family Farm Development in Guangdong
}

\author{
Du Guoming1, a, Li Shanshan ${ }^{1, b}$, Zheng Renjie ${ }^{1, c}$, Du jinpei ${ }^{2, d}$ \\ ${ }^{1}$ School of Humanities and Law, South China Agricultural University, Guangzhou, China \\ ${ }^{2}$ Guangdong Center for Rural Policy Studies, Guangzhou, China \\ a710177330@qq.com, b851136672@qq.com, c1405919558@qq.com, ddk1900@tom.com
}

\begin{abstract}
Key Words: family farm; Guangdong province; SWOT; evaluation
Abstract. The degree of development of agricultural modernization in Guangdong Province is in the front row in China. The relatively developed agricultural economy of the province has resulted in management styles similar to running a family farm. These management styles have already existed for a long time. Some regions have launched pilot cultivation of family farms. This research takes the farm owned by Shanwei Lvshun Planting and Breeding Co., Ltd. as an example and adopts the SWOT method to evaluate the development of family farms in Guangdong Province. In this study, the current situation of Guangdong family farms was investigated through SWOT analysis on a farm in Guangdong. Based on different strategic developments, SWOT analysis was performed to carryout countermeasure selection of family farms.
\end{abstract}

\section{Introduction}

In recent years, Yanbian (Jilin), Songjiang (Shanghai), Langxi (An’hui), Wuhan (Hubei), Ningbo (Zhejiang), and other areas have effectively cultivated family farms. These farms have played a positive role in promoting the development of modern agriculture. These five areas have been universally acknowledged as the headstreams of family farms in China [1].However, upgrading is not easy, and the main resistance comes from the family farms in Guangdong Province which have not achieved a complete and healthy development.

The practice and innovation of the agricultural management pattern in Guangdong is in the front row in China. However, a hysteretic phenomenon was observed in the practice of the agricultural management pattern of family farms. Up to now, Guangdong has not formulated any relevant policy about family farms. This condition indicates that Guangdong is still in the initial stage of exploration with regard to this aspect.

\section{Development Status of Family Farms in Guangdong Province}

\section{Management Styles Similar to Family Farms Have Already Existed For A Long Time}

Advanced secondary and tertiary industries in Guangdong Province have made rural hollowing phenomenon quite serious, and land circulation has become realistic demand[2]. In 2005, Guangdong formulated Administrative Measures for Transference of Rights of Collective Construction Land Use in Guangdong Province (Draft) which accelerated land circulation speed within the scope of the whole province[3].

\section{Diversification of Operating Subjects of Family Farms}

Although there are arguments about operating subjects of family farms, most believe that farmers with agricultural household registration should be subjects and their family numbers should be major labor forces. However, current operating subjects of family farms in Guangdong are of great diversification[4]. 


\section{Polarized Development of "Peculiarity" and "Diversification" Appears Under the Pattern of Breeding and Planting Combination}

Guangdong family farms emphasizes on planting and breeding combination while giving priority to planting industry, and generally breed aquatics doesn't occupy a large proportion. For example, turtle breeding in Fengrun farm in Dongguan only occupies 5mu of the whole farm, about 10\% [5].

\section{SWOT Analysis of Guangdong Family Farms: Take farm of Shanwei Lvshun Planting \& Breeding Co., Ltd As An Example}

Lvshun Planting \& Breeding Co., Ltd, founded in 2012, is located in Jiaozaifu, Shuanghe Village, Huangqiang Town. There are 7 long-term fixed labor forces, and the farm holder and his wife are in charge of farm management and sales of agricultural products. Lvshun Planting \& Breeding Co., Ltd is located in east Guangdong region, namely located in one of the main agricultural production areas in Guangdong Province. Here a SWOT analysis about the farm according to its specific status will be conducted, expecting to have a specific cognition of real development of Guangdong family farms and summarize development strategies for family farms by combining the reality[6, 7].

Analysis of Internal Strengths (S)

Stable Customer Resources. Lvshun Planting \& Breeding Co., Ltd owns fixed customer resources which mainly are wholesalers and supermarkets respectively occupying $70 \%$ and $30 \%$. Products of the farm are mainly sold to Shenzhen and Guangzhou, and sales volumes in the two regions occupy $80 \%$ of the total sales volume, other products are sold in the local region.

Unique Products with High Market Values. Featured products in the farm are okras. This variety is newly introduced variety from Provincial Academy of Agricultural Sciences. Guangdong has not yet promoted its plantation, so it is scarcely seen in market for the moment. However, there are few agricultural products that can compete with it.

Complete Infrastructure. The farm has complete infrastructure. The irrigation system covers the whole farm and this irritation and diversion project is mainly completed by investment of the government, totally spending RMB 300, 000, among which only RMB 50, 000 goes to the farm. However, as the government has also input a large amount of funds in perfecting infrastructure, the burden on the farm is greatly relieved.

Master Advanced Agricultural Technology. The farm at present doesn't have its own research team of agricultural technology, but the farm associate and cooperate with Guangdong Academy of Agricultural Sciences closely.

\section{Analysis of Internal Weaknesses (W)}

Unitary Marketing Pattern. For the moment, although the farm has stable customer resources with marketing channel having a certain guarantee. However, current sales performance is established on the basis of past human resources of the farmer, while unicity of marketing pattern will certainly result in that increasing production volume of the farm will generate unsalable situation. .

High Operating Cost and Low Pure Profits. Annual total output value of the farm is about RMB one million. However, pure profits of the farm only occupies $10 \%-15 \%$ of the total output value while wholesalers and sale terminals occupy the major proportion of the total output value with their profits being doubling or tripling that of the farm.

Small Quantity of Agricultural Machinery and Difficult Access of Large-Scale Agricultural Machinery. At the present, there is a small quantity of agricultural machinery only with 2 small-scale tractors, 1 hay mower, 1 pickup truck used for transportation and 1 small minibus. As large-scale machinery can't be applied, which has greatly increased labor amount of labor forces of the farm.

Land Scale Is Yet to Be Expanded and Circulated Lands Are Hard to Be Smoothened. However, the demand of agricultural products especially okras has exceeded the supply. 


\section{Analysis of External Opportunities (O)}

Low Cost of Land Circulation. Circulation cost of $250 \mathrm{mu}$ lands that are being circulated now is RMB 100/mu with lease period being 20 years, the rent will increase by $20 \%$ in the later 10 years.

East Staff Hiring and Stable Human Resource Cost. Average age of labors hired by the farm now is 43, all of them are middle aged with average salary being RMB 3,500 per month, slightly higher than average local salary level, so labors are quite satisfied with their salaries and they have no intention to quit within a short period, so the farm has relatively stable permanent labors.

Little Competition Within the Industry. At the moment, there are about 30 family farms in Huangqiang Town, but only Lvshun farm concentrates on vegetable plantation, while scale and product advantages of Lvshun farm are quite obvious compared with other traditional vegetable growers with small-scale farming operation, other vegetable growers basically can't constitute any threat.

\section{Analysis of External Threats (T)}

Weak Supporting Force of Measures. Weak supporting force of governmental measures is mainly represented in three aspects: firstly is that registration system for family farms has not yet been formulated.

Weak Risk Resistance Capacity and Imperfect Agricultural Insurance. Risk resistance capacity of the farm is yet to be elevated, which is represented during the process of anti-natural disasters. The farm has suffered two major natural disasters since its foundation: typhoon Utor and typhoon Yutu.

A Lack of Associative Mechanism Among Farms.Family farms in Huangqiang Town manage their own business without little association with farmers' specialized cooperatives, which results in closed information between them and make it easy for malicious competition during selling process.

\section{SWOT Matrix Analysis}

Based on analysis in the above text, here internal strengths during developmental process of Lvshun farm (S) can be listed: stable customer resources, unique products, perfect infrastructure and mastery of advanced agricultural technologies; Internal weaknesses (W): Unitary marketing pattern, high operating cost, low staff quality, hard application agricultural machinery and small land scale; External opportunities (O): Sound economic environment, low expense of land circulation, stable human resources and little competition within the industry; External threats (T): Little supporting force of measures, hard forecast of the market, weak risk resistance capacity, impact of new media and networks and a lack of associative mechanism among farms. Conduct a matrix analysis based on the above analytic results and form into four combinations: Strength-Opportunity (SO) combination, Weakness-Opportunity (WO) combination, Strength-Threat (ST) combination, and Weakness-Threat (WT) combination. The analysis aims at using opportunities to consolidate strength, using opportunities to make up for weaknesses, using strengths to avoid threat and reducing weaknesses to avoid threats.

Table 1 SWOT Analysis Matrix Table of Developmental Countermeasures of Farm of Lvshun Planting \& Breeding Co., Ltd

\section{Internal Strengths Internal Weaknesses}

(S)

(W)

\begin{tabular}{cc}
\hline S1 Stable customer & \multicolumn{1}{c}{ W1 Unitary } \\
resources & marketing pattern \\
S2 Unique products & W2 High operating \\
S3 Perfect & W3 Difficult \\
infrastructure & application of agricultural \\
S4 Master advanced & machinery \\
\end{tabular}


agricultural technologies

\section{Analysis of External}

Opportunities (O)

O1 Sound economic environment

O2 Low expense of land circulation

O3 Stable human resources

O4 Little competition

within the industry

Analysis of External

Threats ( $T$ )

T1 Little supporting

force of measures

T2 Hard to forecast the market

T3 Weak risk

resistance capacity

T4 Impact of new media and networks

T5 A lack of associative mechanism among farms
S01 Properly expand the market

SO2 Further perfect hardware facilities

SO3 Sustain technical advantages of the farm

\author{
WO1 Innovate \\ marketing pattern \\ WO2 Vigorously \\ elevate staff quality \\ WO3 Improve \\ application degree of \\ agricultural machinery
}

ST1 Grasp favorable
factors of measures
ST2 Enhance risk
resistance capacity
$\quad$ ST3 Intensify
industrial alliance and
mutual exchange of
needed products

WT1 Establish market forecasting mechanism

WT2 Introduce

modern enterprise

management system

WT3 Enrich

management styles of the farm

\section{Countermeasure Selection of Farm of Lvshun Planting \& Breeding Co., Ltd Based on SWOT Matrix Analysis}

Selection of Strategic Countermeasures Based on SO. Fist, Use sound economic environment to expand the market. The sound local economic environment can provide stable foundation of human resources and land circulation for development of the farm. Second, Further perfect hardware facilities.

Selection of Strategic Countermeasures Based on WO. Fist, Innovate sales model and save intermediate cost. The root cause of high operating cost of the farm is high intermediate cost, and wholesalers occupy about 30\% of the profits. Second, Vigorously elevate staff quality.

Selection of Strategic Countermeasures Based on ST. Fist, Be good at grasping favorable factors in agricultural policies. Second, Enhance risk resistance capacity. To enhance risk resistance capacity of the farm, it must make "from external to internal" efforts.

Selection of Strategic Countermeasures Based on WT. Fist, Establish market forecasting mechanism. Second, Introduce modern enterprise management system.

\section{Conclusion}

First, Guangdong, a coastal province, is in a good position for reform and for the opening up of China because of its large aggregate economic volume and rapid development. Second, the total value of agricultural output in Guangdong has steadily increased with the advanced second and 
tertiary industries, dynamic township enterprises, and rich varieties of agricultural products. Third, the efficiency of Guangdong's land circulation system has boosted land circulation in Guangdong areas.

Guangdong family farms have achieved substantial development. However, numerous problems still remain which include regional development imbalance.

The industrialized and scale agricultural operation in Guangdong Province is ranked first in the whole of China. The development of family farms requires scale, specialized, industrialized, and mechanized operation of agriculture in Guangdong Province.

\section{Acknowledgements}

This work was financially supported by Guangdong Collaborative innovation and platform environment construction project (2017A040406022) and Key projects of the Ministry of education of the National Education Science 13th Five-Year plan(DIA180381).

\section{References}

[1] Jin Jianfeng, Zhang Lezhu, Hu Haoming. "company + family farm: the new research of Wens group"'J].South Village,2012(4) , pp.12-17.

[2] Hu Xinyan, Luo Biliang, Wang Xiaohai. "The transfer of the farm transfer and the management form of the farm--take Guangdong province as an example"[J].Rural Economy,2013(4) , pp.:2-6.

[3] Li Zhaoting." The typical management form of the industrialization farm in Guangdong province"[J]. Guangdong Technology, 2013(8) , pp.25-29.

[4] Zhu Chunjiang, Ma Wenbin." The opportunities and choice during the development of the family farm in China"[J]. Guizhou Agricultural Science, 2014(1) , pp.21-26.

[5] Yang Jianli, Zhou Maotong. "The obstacles and countermeasures during the development of the family farm in China"[J].Economic Review,2014(2) , pp.:30-35.

[6] Ding Zhifan, Liu Guangjun. "The family farm is the realistic choice during the modernization development of agriculture in China"[J].Agriculture Economy,2014(1), pp.27-35.

[7] Zhang Zhaoxin, Zhang Haiyang. "The countermeasures of the family farm"[J].Rural Business Management, 2013(4), pp.5-12. 